\title{
Diagnostic accuracy of skin-prick testing for allergic rhinitis: a systematic review and meta-analysis
}

Immaculate F. Nevis ${ }^{1 *}$, Karen Binkley ${ }^{2}$ and Conrad Kabali ${ }^{1,3}$

\begin{abstract}
Background: Allergic rhinitis is the most common form of allergy worldwide. The accuracy of skin testing for allergic rhinitis is still debated. Our primary objective was to evaluate the diagnostic accuracy of skin-prick testing for allergic rhinitis using the nasal provocation as the reference standard. We also evaluated the diagnostic accuracy of intradermal testing as a secondary objective.

Methods: We searched EBM Reviews from 2005 to March 2015; Embase from 1980 to March 2015; and Ovid MEDLINE(R) from 1946 to until March 2015. We included any study with at least 10 subjects including children. We excluded non-English studies. We performed data extraction and quality assessment using the QUADAS-2 tool.

Results: We meta-analysed seven studies assessing the accuracy of skin-prick testing using the bivariate randomeffects model, including a total of 430 patients. The pooled estimate for sensitivity and specificity for skin-prick testing was 85 and $77 \%$ respectively. We did not pool results for intradermal testing due to few number of studies $(n=4)$, each with very small sample size. Of these, two evaluated the accuracy of intradermal testing in confirming skin-prick testing results, with sensitivity ranging from 27 to $50 \%$ and specificity ranging from 60 to $100 \%$. The other two evaluated the accuracy of intradermal testing as a stand-alone test for diagnosing allergic rhinitis with sensitivity ranging from 60 to $79 \%$ and specificity ranging from 68 to $69 \%$.
\end{abstract}

Conclusions: Findings from this review suggest that skin-prick testing is accurate in discriminating subjects with or without allergic rhinitis.

Keywords: Skin-prick testing, Allergic rhinitis, Intradermal testing, Review, Meta-analysis, Diagnostic accuracy

\section{Background}

Allergic rhinitis is a collection of symptoms that develop when the immune system becomes sensitized and overreacts to air-borne allergens [1]. It is the most common allergic disorder worldwide, [2] and one among the leading chronic conditions affecting both children and adults [3]. The global prevalence of allergic rhinitis is between 10 and $30 \%$ for adults and as high as $40 \%$ for children [4, 5]. Symptoms of allergic rhinitis usually develop before age 20 years, [6] and peak at age 20-40 years, before gradually declining [7].

\footnotetext{
*Correspondence: immaculatenevis@yahoo.ca

1 Health Quality Ontario, 130 Bloor Street West, Toronto, ON M5S 1N5, Canada

Full list of author information is available at the end of the article
}

The diagnosis of allergic rhinitis is often made on the basis of clinical characteristics and response to pharmacotherapy [7]. Evidence of sensitization to a known allergen usually involves a combination of skin or blood testing and patient's exposure history [8]. Because of ease of administration and being less invasive, skin-prick testing is recommended for diagnosis of allergic rhinitis, followed by intradermal testing to confirm negative skin-prick testing results [9]. There is no universally accepted "gold standard" for detecting allergic rhinitis, although in research studies, nasal provocation is often used as the reference standard. There seems to be no consensus among researchers on the diagnostic accuracy of skin testing for allergies [10-12], including allergic rhinitis [13-15]. The variability in the accuracy of these 
tests across studies can be explained by lack of standardization, stability and composition of allergens, the testing device, the patient population, or the quality of study design. However, we are not aware of any systematic review that has evaluated the diagnostic accuracy of skin testing for allergic rhinitis across a range of studies. To address this issue, we conducted a systematic review and meta-analysis of published studies on the diagnostic accuracy of skin-prick testing in children or adults with suspected symptoms of allergic rhinitis. As a secondary analysis we also evaluated the diagnostic accuracy of intradermal testing for the same group of patients.

\section{Review}

\section{Methods}

We conducted and reported this review according to published guidelines using a pre-specified protocol [16].

\section{Eligibility criteria}

We included any study that reported both sensitivity and specificity of skin-prick testing in at least 10 subjects including adults, children or both with allergic rhinitis using nasal provocation as the reference standard. We included full text papers and abstracts published in English language. We excluded studies enrolling subjects with known allergic status (commonly referred to as "case-control" designs in the diagnostic accuracy literature), and studies that did not include nasal provocation as the reference standard.

\section{Search strategy}

We performed a literature search with the help of medical librarians on April 24, 2015, using All Ovid MEDLINE (from 1946 to present), Embase (from 1980 to present), Cochrane Database of Systematic Reviews (from 2005-present), Database of Abstracts of Reviews of Effects (from 1991-present), CRD Health Technology Assessment Database (from 2001-present), Cochrane Central Register of Controlled Trials (1991-present), and NHS Economic Evaluation Database (from 1995-present). The search strategy included a combination of key words and $\mathrm{MeSH}$ terms and was adapted for each database to account for differences in indexing. We limited our search to English language. We also searched gray literature sources and conference abstracts. Appendix 1 provides details on the search strategies used. We also examined reference lists for any additional relevant studies not identified through the search.

\section{Study selection, data abstraction and analysis}

We screened titles and abstract (CK, IN) and obtained full texts for studies that met the eligibility criteria. We extracted estimates for sensitivity, specificity, and sample size from all eligible studies. We also computed sensitivity and/or specificity for studies that did not report these estimates but provided sufficient information for their derivation. We constructed forest plots to assess heterogeneity in test accuracy across studies. In case of substantial heterogeneity, we proceeded with a subgroup analysis to determine the reason for inconsistency. When homogeneity assumption was deemed appropriate, we pooled studies using the bivariate approach [17]. The pooled results were presented on a summary receiver operating characteristic curve (sROC), which included a $95 \%$ confidence ellipse. When homogeneity assumption failed to hold, we presented sensitivity and specificity separately for each study. The logit transformation was used for the calculation of study specific confidence intervals to account for asymmetry in the distribution of sensitivity and specificity. When estimates were on, or too close to the boundary of the parameter space (i.e., values for sensitivity or specificity were equal to, or approximately equal to 0 or $100 \%$ ), a continuity correction factor of $1 \%$ was applied. All analyses were performed using the MADA package in $\mathrm{R}$ version 3.0.2.

\section{Quality of evidence}

The quality of evidence for each bivariate outcome within studies was examined according to the quality assessment of diagnostic accuracy studies (QUADAS-2) [18]. This tool consists of four key domains: patient selection, index test, reference standard, and flow and timing.

\section{Results}

Study selection

One reviewer (CK) screened and evaluated 2360 citations and assessed 56 full text articles for eligibility. An unbiased sample of 374 citations were screened by a second reviewer (IN) using the method of Nevis et al. [19]. The chance-corrected agreement for titles and abstracts was good (estimated kappa $=75 \%$; $95 \%$ CI 50-100 \%). We resolved disagreements by consensus. Of the 56 full text articles, we excluded 42 as they were not relevant, three articles had insufficient information on outcomes and three were case control studies. Figure 1 summarizes the selection process. Eight articles were eligible to be included in the systematic review [15, 20-25]. Only seven of the eight articles were included in the meta-analysis because one study restricted their allergen to alternaria that was not evaluated by any of the other eligible studies in this review, and whose findings deviated substantially from the remaining studies [14].

\section{Description of studies, methods and participants}

Eight studies from four countries focused our primary research question (i.e., accuracy of skin prick testing), 


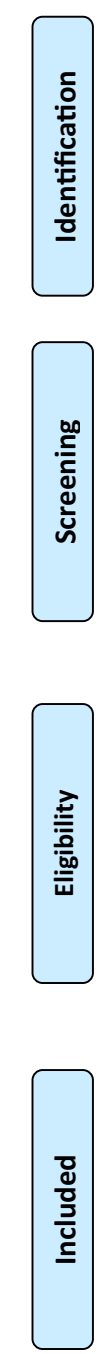

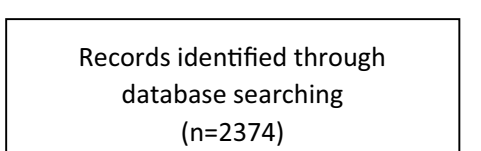

$(n=2374)$
Additional records identified

through other sources

$(n=0)$

Records after duplicates removed

$(n=14)$
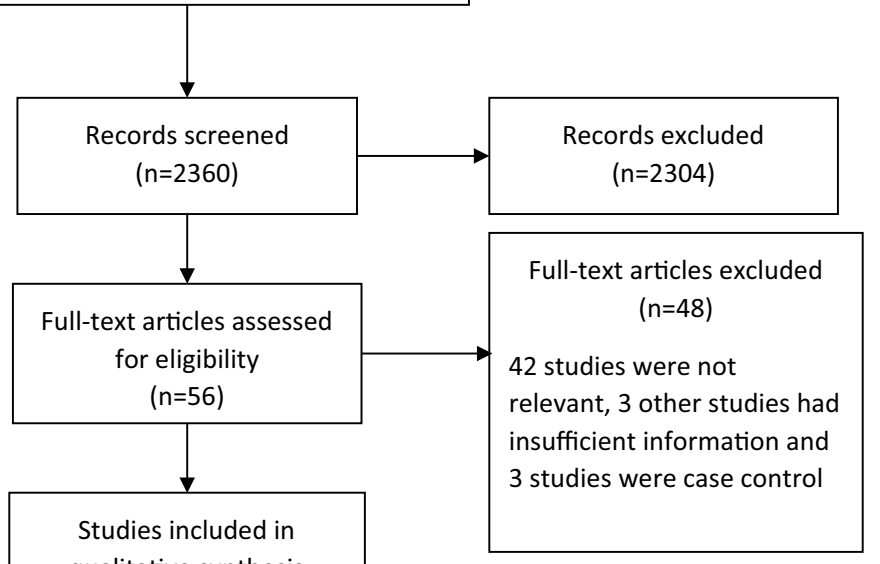

qualitative synthesis

(Systematic review) $(n=8)$

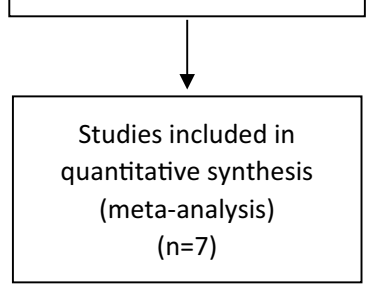

Fig. 1 PRISMA flow diagram of studies identified, included and excluded

recruiting a total of 609 patients (range 37-141) (Table 1). Four of the included studies [14, 15, 20, 24] focused on secondary research question (i.e., accuracy of intradermal testing) (Table 2). Most studies were done in North America $(n=5)$, followed by one study each from Italy, Sweden and United Kingdom. All study participants were recruited using non-random sampling approaches. Five studies recruited participants in a clinical setting $[15,21-$ $23,25]$. Most $(\mathrm{n}=11)$ studies reported age of the study population, ranging from 9 to 70 years. The percentage of males ranged from 18 to $70 \%$. Seven of eight provided information on cut-off point for positive skin prick testing [20-25]. Five studies evaluated a single allergen, of which two evaluated cat allergens $[24,25]$ and the remaining three evaluated Timothy grass, ragweed and alternaria each $[14,15,20]$. Three studies evaluated two or more allergens [21-23] which included grass, mugwort, birch, pellitory, timothy, sweet vernal, cocksfoot, meadow fescue, rye, meadow and dermatophagoides pteronyssinus (Table 1). The most frequently evaluated allergen extract was timothy grass, reported in three studies [20, 22, 23] and cat, reported in two studies [24, 25].

\section{Primary analysis: diagnostic accuracy of skin-prick testing}

We conducted a meta-analysis of studies reporting sensitivity and specificity of skin-prick testing. The pooled estimate of sensitivity and specificity for this test was 88.4 and $77.1 \%$ respectively (Fig. 2). We also conducted a sensitivity analysis by including in the meta-analysis, the study that tested for alternaria [14]. Inclusion of this study did not significantly alter the estimates for accuracy. The pooled estimate for sensitivity and specificity 


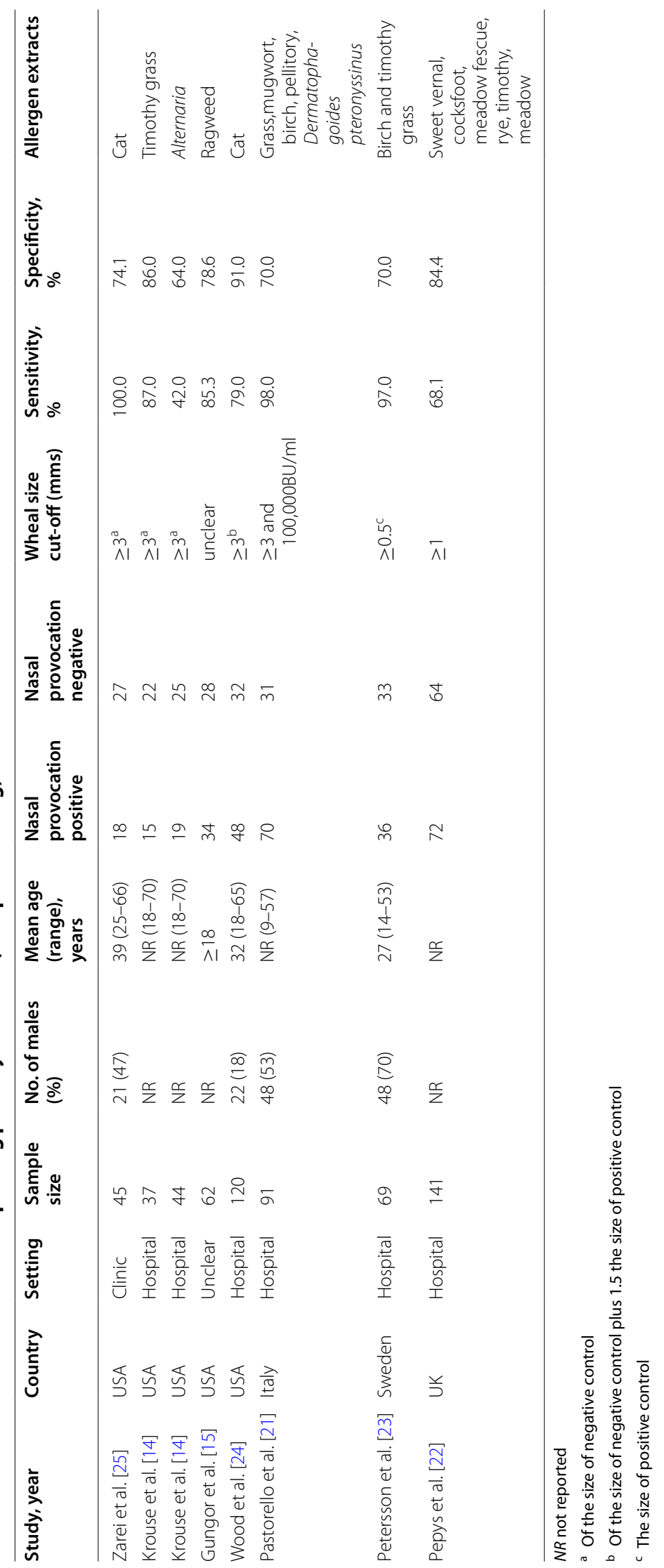


Table 2 Characteristics of studies reporting secondary outcome (intradermal testing)

\begin{tabular}{|c|c|c|c|c|c|c|c|c|c|c|c|}
\hline Study, year & Country & Setting & $\begin{array}{l}\text { Sample } \\
\text { size }\end{array}$ & $\begin{array}{l}\text { Number } \\
\text { of males }\end{array}$ & $\begin{array}{l}\text { Age } \\
\text { range, } \\
\text { years }\end{array}$ & $\begin{array}{l}\text { Nasal } \\
\text { provocation } \\
\text { positive }\end{array}$ & $\begin{array}{l}\text { Nasal } \\
\text { provocation } \\
\text { negative }\end{array}$ & $\begin{array}{l}\text { Wheal size } \\
\text { cut-off } \\
\text { (mms) }\end{array}$ & $\begin{array}{l}\text { Sensitivity, } \\
\%\end{array}$ & $\begin{array}{l}\text { Specificity, } \\
\%\end{array}$ & $\begin{array}{l}\text { Allergen } \\
\text { extracts }\end{array}$ \\
\hline Krouse et al. [14] & USA & Hospital & 37 & NR & NR (18-70) & 2 & 19 & $\geq 3^{a}$ & 50.0 & 100.0 & $\begin{array}{c}\text { Timothy } \\
\text { grass }\end{array}$ \\
\hline Krouse et al. [14] & USA & Hospital & 44 & NR & NR (18-70) & 11 & 16 & $\geq 3^{\mathrm{a}}$ & 27.0 & 69.0 & Alternaria \\
\hline Gungor et al. [15] & USA & Unclear & 62 & $N R$ & $\geq 18$ & 34 & 28 & $\geq 2$ & 79.4 & 67.9 & Ragweed \\
\hline Wood et al. [24] & USA & Hospital & 120 & $22(18)$ & $32(18-65)$ & 10 & 29 & $\geq 6$ & 60.0 & 68.9 & Cat \\
\hline
\end{tabular}

$N R$ not reported

a Of the size of negative control

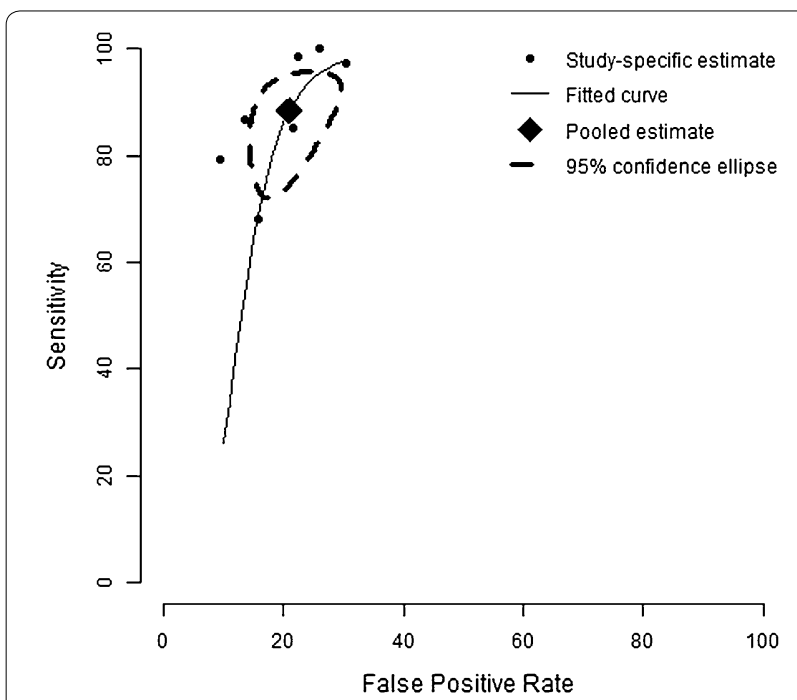

Fig. 2 Summary receiver operating characteristic curve (sROC) of seven studies evaluating the accuracy of skin-testing for allergic rhinitis, plotted using a bivariate normal distribution model. Estimate of the pooled pair of sensitivity and specificity is 88.4 and $77.1 \%$ changed to 85.0 and $77.3 \%$ respectively (Fig. 3). The forest plots for heterogeneity are presented in Figs. 4 and 5.

Five studies that evaluated the accuracy of skin-prick testing $[14,15,20,24,25]$ restricted the analysis to singleallergen extracts. The sensitivity and specificity ranged from $79 \%$ (95 \% CI 66-88 \%) to $100 \%(82-100 \%)$ and $79 \%$ (95 \% CI 66-88 \%) to $91 \%$ (76-97\%) respectively, excluding Krouse et al. [14]. When Krouse et al. [14] was included, the minimum values for sensitivity and specificity were altered to $42 \%$ (95\% CI 23-64\%) and $64 \%$ (95\% CI 45-80\%) respectively.

Three studies that evaluated the accuracy of skin-prick testing examined multiple-allergen extracts [21-23]. The reported sensitivity ranged from $68 \%(57-78 \%)$ to $97 \%$ (86-100\%), and specificity ranged from $70 \%$ (95\% CI $54-86 \%)$ to $84 \%$ (95\% CI 74-91\%) respectively.

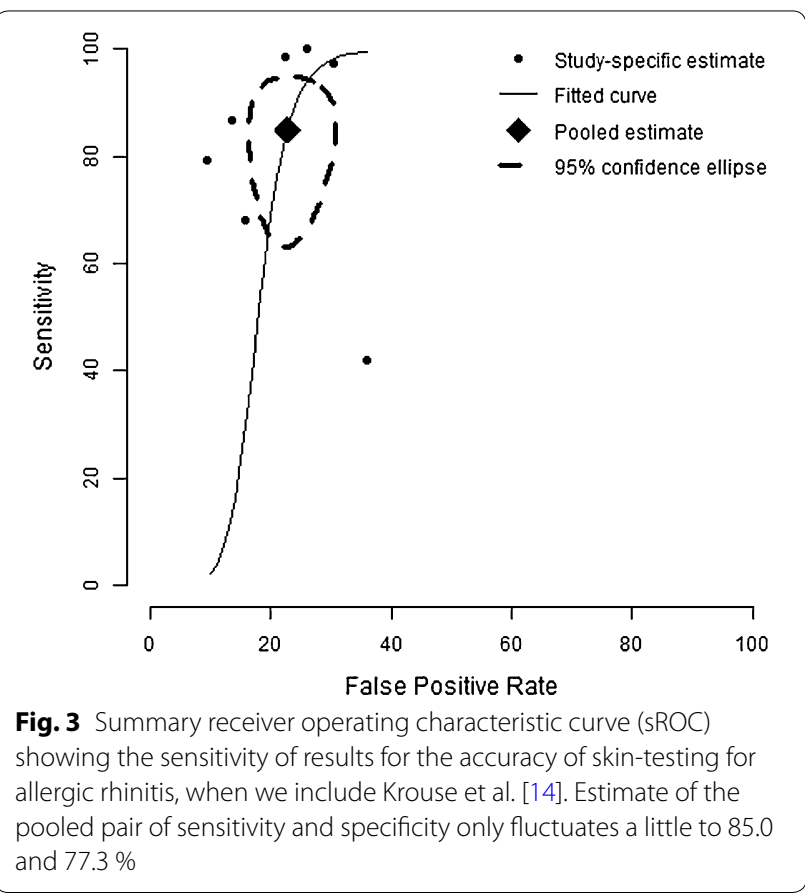

\section{Secondary analysis: diagnostic accuracy of intradermal testing}

We conducted a systematic review of four studies that reported sensitivity and specificity of intradermal testing. When intradermal testing was used to confirm negative skin-prick testing results, the estimates for sensitivity ranged from $27 \%$ (95\% CI 10-57\%) to $50 \%$ (sample size was too small for estimation of CI using asymptotic-based statistical tests) and those for specificity ranged from $69 \%$ (95\% CI 51-83\%) to $100 \%$ (95\% CI 83-100\%). When the test was evaluated as a standalone tool for diagnosing allergic rhinitis, the estimate for sensitivity was between $60 \%$ (95\% CI 31-83\%) and $79 \%$ (95\% CI 63-90\%), and that for specificity was $68 \%$ (95\% CI 49-82 \%). All four studies [14, 15, 20, 24] restricted the analysis to single-allergen extracts. 

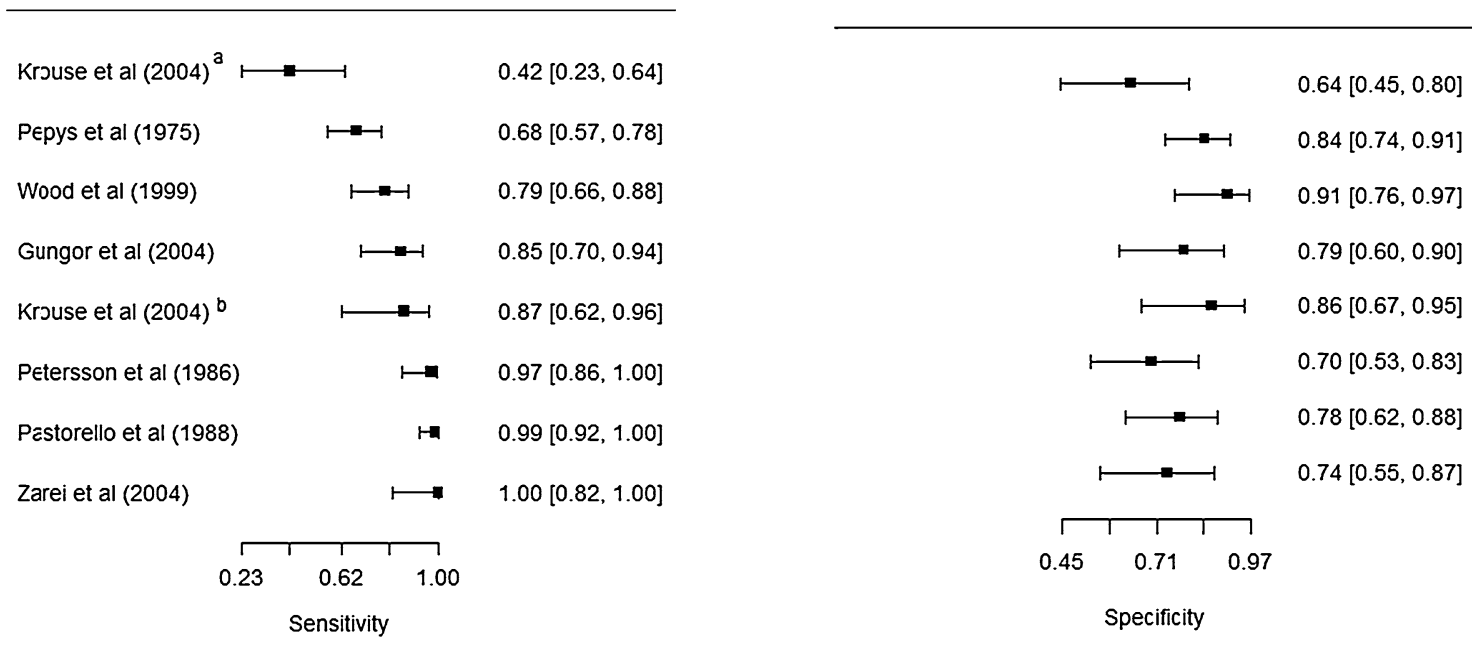

Fig. 4 Forest plots for studies evaluating the accuracy of skin prick tests. Estimates from Krouse et al. [14] ${ }^{\text {a }}$ deviate considerably from the rest (its inclusion attenuates the negative correlation between sensitivity and specificity)

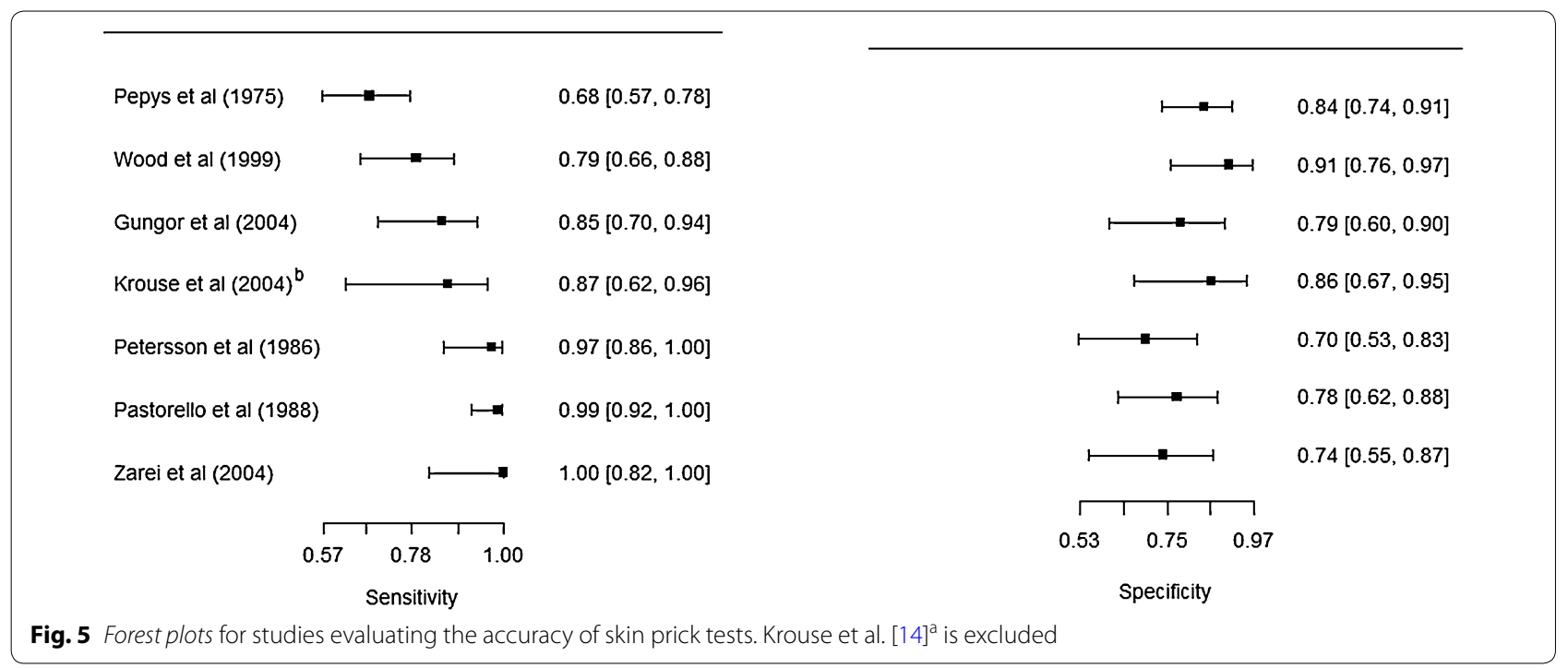

\section{Risk of bias and applicability concerns}

We summarize assessment of risk of bias in Figs. 6, 7 and 8. For skin-prick testing the risk of bias was "unclear" in five studies [15, 22-25]. For intradermal testing the risk of bias was "high" in one study, [14] and "unknown" in two studies $[15,25]$. Applicability concerns were "high" in two studies $[14,20]$.

We used Fig. 8 to evaluate the potential for heterogeneity in estimates for the accuracy of skin-prick testing. The inclusion of Krouse et al. [14] introduced a discernible heterogeneity across studies. Specifically, the $95 \%$ confidence (CI) for sensitivity barely overlapped with CIs of other studies, and its inclusion swayed the correlation between sensitivity and specificity toward a positive value-violating a requirement for meta-analysis of diagnostic accuracy studies that the correlation should be non-positive for homogeneity assumption to hold. When this study was removed from the analysis, the negative correlation was observed (Fig. 5).

Five studies either did not report [15] or use [15, 22-24] a $3 \mathrm{~mm}$ cut-off value for the wheal size diameter recommended by the American Academy of Allergy, Asthma and Immunology (AAAAI) and the American College of Allergy, Asthma, and Immunology (ACAAI) [9]. Given the relation between the cut-off value and sensitivity and specificity, and because a $3 \mathrm{~mm}$ cut-off value might not be optimal in all settings, [26] we classified these studies as "unclear-risk of bias". Moreover, the sample size for two studies evaluating the accuracy of intradermal testing $[14,20]$ was too small, calling into question whether 


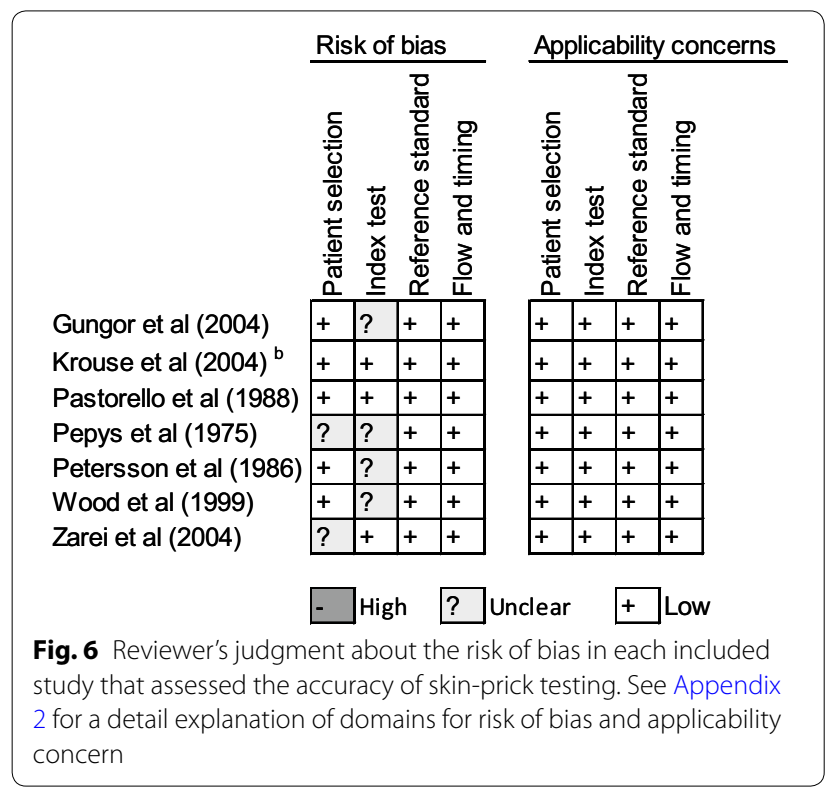

findings from these studies apply to the majority of suspected allergic rhinitis patients presenting in clinics. We classified both studies as "high-risk of bias".

\section{Discussion}

Findings from this review suggest that skin-prick testing is reasonably accurate in identifying patients with suspected symptoms of allergic rhinitis. The level of accuracy reported in studies eligible for meta-analysis ranged from sensitivity of 68 to $100 \%$ and specificity of 70 to $91 \%$. Although we could not establish the source of heterogeneity in testing accuracy across studies, several factors

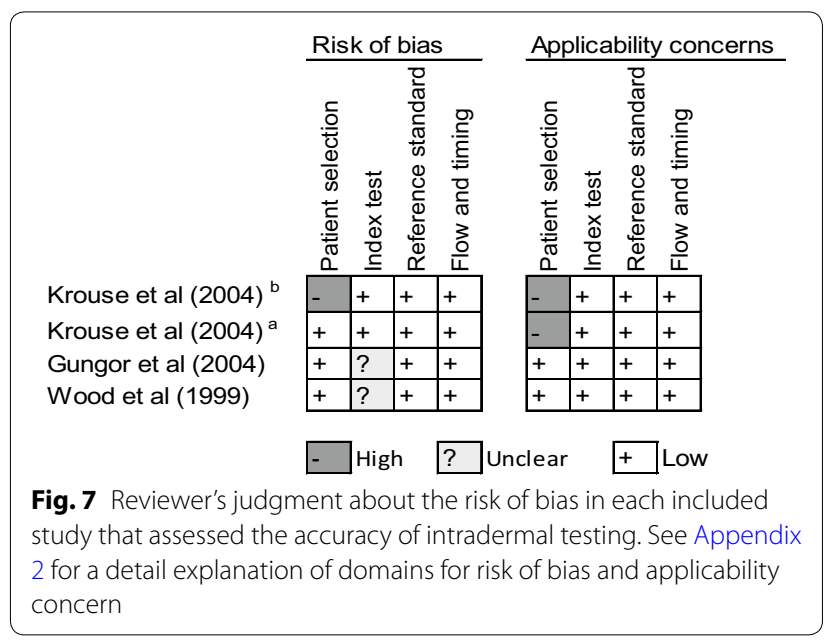

that influence accuracy of skin-prick testing have been reported in the literature $[9,27]$. These include skill of the tester, the testing device, colour of the skin, skin reactivity on the day of testing, potency, and stability of test reagents.

To our knowledge this is the first systematic review and meta-analysis to evaluate the accuracy of skin-prick testing. Given lack of consensus among researchers and health practitioners on the performance of this test, findings from this review broaden our knowledge on the accuracy of this test across a large body of evidence. This is especially important given that effectiveness of intervention such as immunotherapy, avoidance, or pharmacotherapy largely depends on the correct diagnosis. Thus proper diagnosis can alleviate financial burden and loss in quality of life for millions of patients affected by allergic rhinitis.

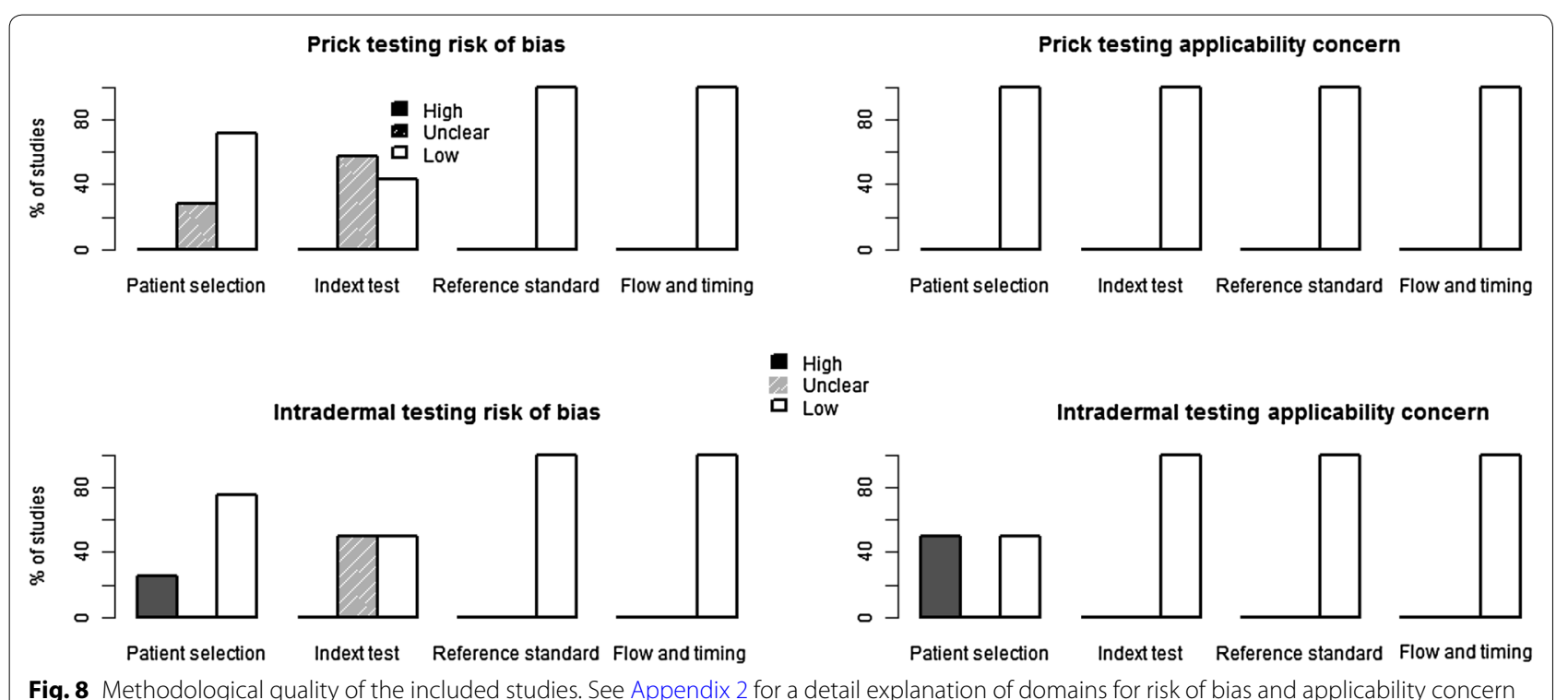

Fig. 8 Methodological quality of the included studies. See Appendix 2 for a detail explanation of domains for risk of bias and applicability concern 
Although there are no restrictions on age limits for skin-prick testing, literature suggests that skin reaction diminishes for young children [28]. That is, a $3 \mathrm{~mm}$ threshold for wheal size diameter is likely to yield a high rate of false positives in this group of patients. However, we were unable to assess the accuracy of skin-prick testing in children younger than 9 years due to the fact minimum age for eligible studies for this review was 9 years.

It should be noted that a $3 \mathrm{~mm}$ cutoff criteria recommended in guidelines is mainly based on reproducibility in relation to nasal provocation rather than clinical relevance [29]. That is, larger wheal sizes may predict a positive response to nasal provocation but not necessarily severity of clinical symptoms. The extent of agreement between wheal size and clinical symptoms may depend on population characteristics and allergen extracts.

We note the following limitations. First, we were unable to determine the degree of accuracy of intradermal testing because of the limitations in the four included studies. Hence, well designed methodologically rigorous studies are required to firmly establish the accuracy of intradermal testing. Second, we used nasal provocation as the reference standard. However, this test may not always represent the natural exposure to allergens. Despite this limitation, nasal provocation is still considered as the best "gold standard" available by several guidelines. Finally, there was a substantial variation in allergen extracts among studies. Nonetheless, skin-prick testing results remained fairly accurate regardless of the type of extracts.

\section{Conclusions}

In conclusion this review supports findings from several studies that skin-prick testing is accurate for diagnosing patients with allergic rhinitis. Several factors have been reported to influence the accuracy of prick testing, including skill of the tester, the testing device, color of the skin, skin reactivity on the day of testing, potency, and stability of test reagents. We were unable to determine the degree of accuracy of intradermal testing because of the limitations in the four included studies. Welldesigned methodologically rigorous studies are required to firmly establish the accuracy of allergy skin testing and especially intradermal testing.

\section{Abbreviations}

CRD Database: Centre for Reviews and Dissemination Database; NHS: National Health Service; MeSH: medical subject headings; sROC: summary receiver operating characteristic curve; QUADAS-2: quality assessment of diagnostic accuracy studies; 95 \% Cl: 95 \% confidence interval; ACAAl: American College of Allergy, Asthma, and Immunology; AAAAl: American Academy of Allergy, Asthma and Immunology.

\section{Authors' contributions}

IN drafted the manuscript, conducted second review of citations and addressed comments from coauthors; KB contributed to intellectual content and helped with revision of manuscript; CK did the initial literature review, abstracted data from full text and helped with addressing comments from coauthors. All authors read and approved the final manuscript.

\section{Author details}

${ }^{1}$ Health Quality Ontario, 130 Bloor Street West, Toronto, ON M5S 1N5, Canada. ${ }^{2}$ Department of Medicine, University of Toronto, Toronto, ON, Canada. ${ }^{3}$ Dalla Lana School of Public Health, University of Toronto, Toronto, ON, Canada.

\section{Acknowledgements}

We would like to thank Caroline Higgins for her support during the literature search.

\section{Competing interests}

The authors declare that they have no competing interests.

\section{Disclaimer statement}

The conclusions expressed in this publication do not necessarily represent the opinions of Health Quality Ontario. No endorsement is intended or should be inferred.

\section{Appendix 1: Search strategy}

Database: EBM Reviews-Cochrane Central Register of Controlled Trials <March 2015>, EBM ReviewsCochrane Database of Systematic Reviews $<2005$ to March 2015>, EBM Reviews-Database of Abstracts of Reviews of Effects $<1$ st Quarter 2015>, EBM ReviewsHealth Technology Assessment <1st Quarter 2015>, EBM Reviews-NHS Economic Evaluation Database $<1$ st Quarter 2015>, Embase <1980 to 2015 Week 16>, All Ovid MEDLINE(R) $<1946$ to Present $>$

\section{Appendix 2}

See Table 3. 
Search Strategy:

1 exp Rhinitis/ (95436)

2 (rhiniti* or rhinosinusiti* or poll?nosis or hay fever or hayfever or ((seasonal or inhalant* or respirat*) adj3 allerg*)).tw. (85040)

3 (grass* or tree or trees or pollen\$1).tw. (261672)

4 or/1-3 (372633)

5 Skin Tests/ (64076)

6 exp Intradermal Tests/ (6027)

7 (((test or tests or testing) adj3 (skin or prick or passive transfer or intradermal or intercutaneous or epicutaneous or percutaneous or allerg* or provocat*)) or SPT or SPTs or IDST or IDSTs).tw. (95579)

8 Bronchial Provocation Tests/ (12348)

$9 \quad$ Nasal Provocation Tests/ (2731)

10 ((allerg* or provocat* or nasal or inhalant*) adj3 challenge*).tw. (12619)

11 Radioallergosorbent Test/ (9842)

12 (radioallergosorbent* or radioimmunosorbent* or RAST or RASTs).tw. (9708)

13 or/5-12 (158479)

14 "Sensitivity and Specificity"/ (516790)

15 "Predictive Value of Tests"/ (225688)

16 likelihood functions/ (131637)

17 False Positive Reaction/ (67227)

18 False Negative Reaction/ (58551)

19 (sensitivit* or specificit* or accurac* or validit* or valida* or predictive value* or PPV or NPV or likelihood ratio* or ROC curve* or AUC or (false adj positive*) or (false adj negative*)).tw. (3141298)

20 gold standard.ab. (96368)

21 or/14-20 (3658119)

224 and 13 and $21(5172)$

23 (Comment or Editorial or Letter or Congresses).pt. (2809062) 
$2422 \operatorname{not} 23(5128)$

2524 use pmoz,cctr,coch,dare,clhta,cleed (2434)

26 exp Rhinitis/ (95436)

27 (rhiniti* or rhinosinusiti* or poll?nosis or hay fever or hayfever or ((seasonal or inhalant* or respirat*) adj3 allerg*)).tw. (85040)

28 (grass* or tree or trees or pollen\$1).tw. (261672)

29 or/26-28 (372633)

30 Allergy Test/ (3288)

31 Skin Test/ (64067)

32 Prick Test/ (14084)

33 Intracutaneous Test/ (2696)

34 (((test or tests or testing) adj3 (skin or prick or passive transfer or intradermal or intercutaneous or epicutaneous or percutaneous or allerg* or provocat*)) or SPT or SPTs or IDST or IDSTs).tw. (95579)

35 provocation test/ (24466)

36 nose provocation test/ (919)

37 ((allerg* or provocat* or nasal or inhalant*) adj3 challenge*).tw. (12619)

38 Radioallergosorbent Test/ (9842)

39 (radioallergosorbent* or radioimmunosorbent* or RAST or RASTs).tw. (9708)

40 or/30-39 (168806)

41 "sensitivity and specificity"/ (516790)

42 Diagnostic Accuracy/ (188623)

43 Diagnostic Test Accuracy Study/ (32579)

44 (sensitivit* or specificit* or accurac* or validit* or valida* or predictive value* or PPV or NPV or likelihood ratio* or ROC curve* or AUC or (false adj positive*) or (false adj negative*)).tw. (3141298)

45 gold standard.ab. (96368)

46 or/41-45 (3492743)

$47 \quad 29$ and 40 and 46 (5134)

48 (Comment or Editorial or Letter or Conference abstract).pt. (4558513)

4947 not $48(4433)$

5049 use emez (2235)

5125 or 50 (4669)

52 limit 51 to english language [Limit not valid in CDSR,DARE; records were retained] (3913)

53 remove duplicates from 52 (2421) 


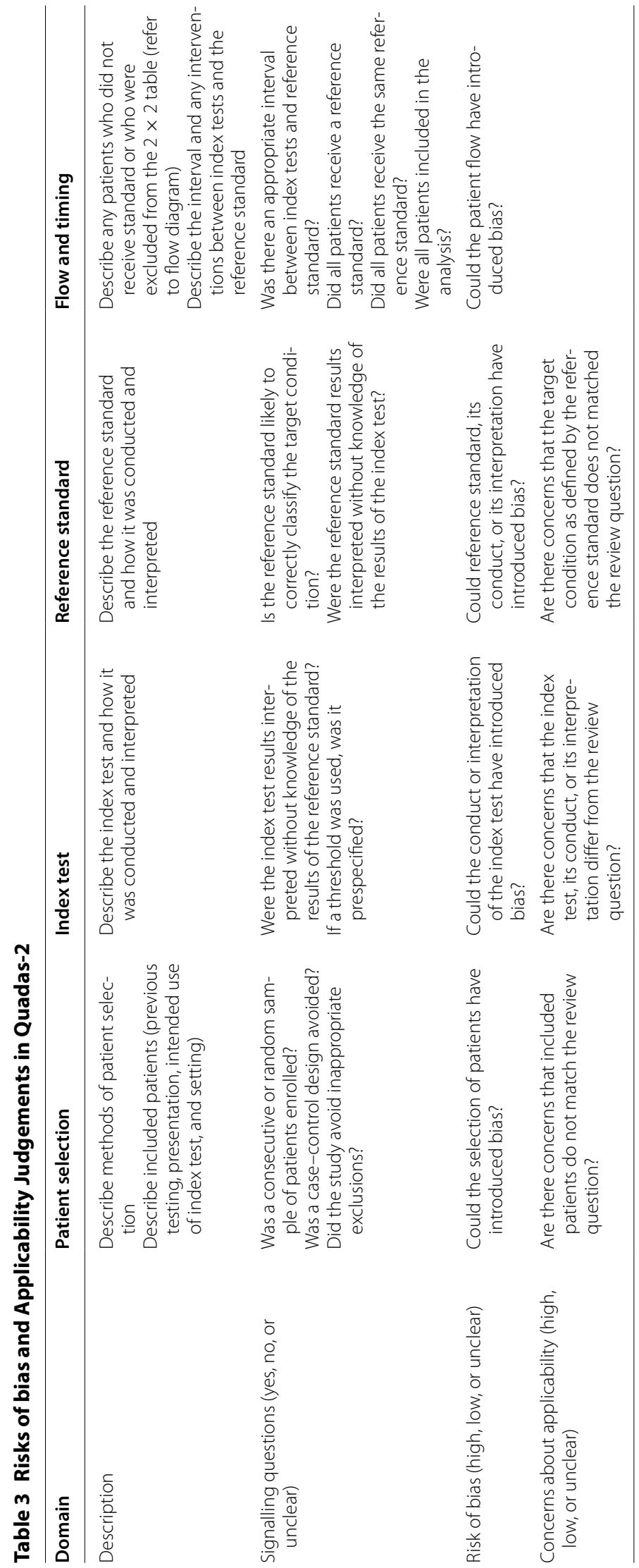


Received: 26 November 2015 Accepted: 1 April 2016

Published online: 27 April 2016

\section{References}

1. Bousquet J, Khaltaev N, Cruz A, Denburg J, Fokkens W, Togias A, et al. Allergic rhinitis and its impact on asthma (ARIA) 2008. Eur J Allergy Clin Immunol. 2008:63(s86):8-160.

2. World Allergy Organization. WAO white book on allergy: update 2013 executive summary. Milwaukee, Wisconsin; 2013. p. 242.

3. Blaiss MS. Allergic rhinitis: direct and indirect costs. Allergy Asthma Proc. 2010:31(5):375-80.

4. Meltzer EO, Blaiss MS, Derebery MJ, Mahr TA, Gordon BR, Sheth KT, et al. Burden of allergic rhinitis: results from the pediatric allergies in America survey. J Allergy Clin Immunol. 2009;124:S43-70.

5. Keith PK, Desrosiers M, Laister T, Schellenberg RR, Waserman S. The burden of allergic rhinitis (AR) in Canada: perspectives of physicians and patients. Allergy Asthma Clin Immunol. 2012;8(7):1-11

6. Skoner DP. Allergic rhinitis: definition, epidemiology, pathophysiology, detection and diagnosis. J Allergy Clin Immunol. 2001;108:S2-8.

7. Wheatley LM, Togias A. Allergic rhinitis. N Engl J Med. 2015;372(5):456-63.

8. Long A, McFadden C, DeVine D, Chew P, Kupelnick B, Lau J. Management of allergic and nonallergic rhinitis. Rockville: agency for healthcare research and quality, services DoHaH. 2002. p. 54

9. Bernstein IL, Li JT, Bernstein DI, Hamilton R, Spector SL, Tan R, et al. Allergy diagnostic testing: an updated practice parameter. Ann Allergy Asthma Immunol. 2008;100(3):S1-148.

10. Eaton KE. Accuracy of prick skin tests for ingestant hypersensitivity diagnosis. J Nutr Environ Med. 2004;14(2):79-82.

11. Majamaa H, Moisio $P$, Kautiainen $H$, Majamaa $H$, Turjanmaa $K$, Holm K. Cow's milk allergy: diagnostic accuracy of skin prick and patch tests and specific lgE. Allergy. 1999;54(4):346-51.

12. Soares-Weiser K, Takwoingi Y, Panesar SS, Muraro A, Werfel T, HoffmannSommergruber $\mathrm{K}$, et al. The diagnosis of food allergy: a systematic review and meta-analysis. Allergy. 2013;69(1):76-86.

13. Kwong KYC, Jean T, Redjal N. Variability in measurement of allergen skin testing results among allergy-immunology specialists. J Allergy Ther 2014;5(1):1-5.

14. Krouse JH, Shah AG, Kerswill K. Skin testing in predicting response to nasal provocation with alternaria. Laryngoscope. 2004;114(8):1389-93.

15. Gungor A, Houser SM, Aquino BF, Akbar I, Moinuddin R, Mamikoglu B, et al. A comparison of skin endpoint titration and skin-prick testing in the diagnosis of allergic rhinitis. Ear Nose Throat J. 2004:83(1):54-60.
16. Moher D, Liberati A, Tetzlaff J, Altmann DG. Preferred reporting items for systematic reviews and meta-analyses: the PRISMA statement. Ann Intern Med. 2009:151(4):264-9.

17. Reitsma JB, Glas AS, Rutjes AWS, Scholten RJPM, Bossuyt PM, Zwinderman $\mathrm{AH}$. Bivariate analysis of sensitivity and specificity produces informative summary measures in diagnostic reviews. J Clin Epidemiol. 2005:58:982-90

18. Whiting P, Rutjes A, Westwood M, Mallett S, Deeks J, Reitsma J, et al. QUADAS-2: a revised tool for the quality assessment of diagnostic accuracy studies. Ann Intern Med. 2011;155:529-36.

19. Nevis IF, Sikich N, Ye C, Kabali C. Quality control tool for screening titles and abstracts by second reviewer: QCTSTAR. J Biom Biostat. 2015;6:230. doi:10.4172/2155-6180.1000230.

20. Krouse JH, Sadrazodi K, Kerswill K. Sensitivity and specificity of prick and intradermal testing in predicting response to nasal provocation with timothy grass antigen. Otolaryngol-Head Neck Surg. 2004;131(3):215-9.

21. Pastorello EA, Codecasa LR, Pravettoni V, Qualizza R, Incorvaia C, Ispano M et al. Clinical reliability of diagnostic tests in allergic rhinoconjunctivitis. Boll Ist Sieroter Milan. 1988;67(5-6):377-85.

22. Pepys J, Roth A, Carroll KB. RAST, skin and nasal tests and the history in grass pollen allergy. Clin Allergy. 1975;5(4):431-42.

23. Petersson G, Dreborg S, Ingestad R. Clinical history, skin prick test and RAST in the diagnosis of birch and timothy pollinosis. Allergy: Eur J Allergy Clin Immunol. 1986:41(6):398-407.

24. Wood RA, Phipatanakul W, Hamilton RG, Eggleston PA. A comparison of skin prick tests, intradermal skin tests, and RASTs in the diagnosis of cat allergy. J Allergy Clin Immunol. 1999;103(5 I):773-9.

25. Zarei M, Remer CF, Kaplan MS, Staveren AM, Lin CKE, Razo E, et al. Optima skin prick wheal size for diagnosis of cat allergy. Ann Allergy Asthma Immunol. 2004;92(6):604-10.

26. Haahtela T, Burbach GJ, Bachert C, Bindslev-Jensen C, Bonini S, Bousquet $J$, et al. Clinical relevance is associated with allergen-specific wheal size in skin prick testing. Clin Exp Allergy. 2014:44(3):407-16.

27. Bodtger U, Poulsen LK, Malling HJ. Asymptomatic skin sensitization to birch predicts later development of birch pollen allergy in adults: a 3-year follow-up study. J Allergy Clin Immunol. 2003;111(1):149-54.

28. Van Asperen PP, Kemp AS, Mellis CM. Skin test reactivity and clinical allergen sensitivity in infancy. J Allergy Clin Immunol. 1984;73(3):381-6.

29. Dreborg S. Diagnosis of food allergy: tests in vivo and in vitro. Pediatr Allergy Immunol. 2001;12(Suppl.14):24-30.

\section{Submit your next manuscript to BioMed Central and we will help you at every step:}

- We accept pre-submission inquiries

- Our selector tool helps you to find the most relevant journal

- We provide round the clock customer support

- Convenient online submission

- Thorough peer review

- Inclusion in PubMed and all major indexing services

- Maximum visibility for your research

Submit your manuscript at www.biomedcentral.com/submit
BioMed Central 